\title{
Ineffective breathing pattern in cardiac postoperative patients: Diagnostic accuracy study
}

\author{
Vanessa Emille Carvalho de Sousa, PhD, RN ${ }^{\mathrm{a}, *}$, Lívia Maia Pascoal, PhD, RN ${ }^{\mathrm{b}}$, Ranielly Vidal do Nascimento, $\mathrm{RN}^{\mathrm{c}}$, \\ Talita Ferreira Oliveira de Matos, $\mathrm{RN}^{\mathrm{c}}$, Beatriz Amorim Beltrão, $\mathrm{PhD}, \mathrm{RN}^{\mathrm{d}}$, \\ Viviane Martins da Silva, $\mathrm{PhD}, \mathrm{RN}^{\mathrm{c}}$, Marcos Venícios de Oliveira Lopes, $\mathrm{PhD}, \mathrm{RN}^{\mathrm{c}}$
}

${ }^{\text {a }}$ University of Illinois at Chicago, Chicago, IL, USA 60612-7350

${ }^{\mathrm{b}}$ Federal University of Maranhão, Imperatriz, Maranhão, Brazil 65900-000

' Federal University of Ceará, Fortaleza, Ceará, Brazil 60430-160

d Hospital Universitário Walter Cantídio, Fortaleza, Ceará, Brazil 60430-370

\section{A R T I C L E I N F O}

\section{Article history:}

Received 29 March 2016

Revised 6 June 2016

Accepted 11 July 2016

\section{Keywords:}

Nursing assessment

Nursing diagnosis

Respiratory signs and symptoms

Postoperative care

\begin{abstract}
A B S T R A C T
Purpose: The aim of this study was to analyze the accuracy of the defining characteristics of ineffective breathing pattern (IBP) in postoperative cardiac patients.

Methods: A diagnostic accuracy study was performed with 98 patients. Measures of sensitivity, specificity, predictive values, likelihood ratios, diagnostic odds ratio, and area under the ROC curve were calculated.

Results: IBP was present in $23.5 \%$ of the patients. Alterations in depth of breathing (sensitivity $96 \%$, negative likelihood ratio $0.11 \%$ ) and pursed-lip breathing (sensitivity $99 \%$, negative likelihood ratio $0.07 \%$ ) were the most sensitive defining characteristics for IBP, while altered chest excursion (specificity 97\%, positive likelihood ratio $11.41 \%$ ) and prolonged expiration phase (specificity $99 \%$, positive likelihood ratio $42.39 \%$ ) were the most specific.

Conclusion: Some clinical indicators were more related to the presence or absence of IBP than others. Knowledge of such measures can help nurses to assess patients more accurately.
\end{abstract}

(C) 2016 Elsevier Inc. All rights reserved.

\section{Introduction}

The identification of human responses to health problems or events from the life cycle, also known as nursing diagnoses, is the basis for nurses' decisions (Herdman \& Kamitsuru, 2014). To define appropriate interventions and monitor the effects of these, it is necessary to establish an accurate representation of the phenomenon of interest. Thus, it is known that the identification of the real health state of the patient contributes to a more efficient care plan (Sousa et al., 2013).

Postoperative respiratory events are expected for almost all cardiac surgical patients. This kind of dysfunction is usually well tolerated when the patient has an adequate pulmonary reserve, but for patients with a history of respiratory disease, postoperative pneumonia, or

Funding: Financial support for this research was provided by Conselho Nacional de Desenvolvimento Científico e Tecnológico (CNPq-Brazil; Process 472257/2009-9). VECS is a post-doctoral research fellow supported by CNPq-Brazil.

Conflict of interest: None.

* Corresponding author at: 845 S Damen Avenue, Room 939, Chicago, IL, USA 60612 7350. Tel.: +1 7738140517.

E-mail addresses: vanessaemille@gmail.com (V.E.C. de Sousa), livia_mp@hotmail.com (L.M. Pascoal), ranielly_vidal@hotmail.com (R.V. do Nascimento),

talitaferreiraoliveira@gmail.com (T.F.O. de Matos), beatriz.enfermagem@yahoo.com.br (B.A. Beltrão), viviane.silva@ufc.br (V.M. da Silva), marcos@ufc.br (M.V.O. Lopes). cardiogenic pulmonary edema, the respiratory function can be impaired severely. Postoperative respiratory events are caused by multiple factors including: general anesthesia, use of central respiratory depressants, sternotomy, use of drainage tubes, cardiopulmonary bypass, blood-derivative transfusion, diaphragm dysfunction, chronic obstructive pulmonary disease, and obesity (Stephens, Shah, \& Whitman, 2013).

Postoperative respiratory problems can be early detected based on consistent defining characteristics. Some of these problems represent nursing diagnoses like ineffective breathing pattern (IBP), for which specific actions should be taken. IBP was introduced in the NANDA-I taxonomy in 1980, and passed through three revisions, being the last one dated in 2010. IBP describes a condition in which the inspiration and/or the expiration do not provide adequate ventilation (Herdman \& Kamitsuru, 2014), and it has been investigated in a number of studies (Beltrao, Silva, Araujo, \& Oliveira Lopes, 2011; Pascoal et al., 2014; Zeitoun, Barros, Michel, \& Bettencourt, 2007). However, there is a lack of studies focusing on the defining characteristics of IBP in cardiac surgery adult patients.

The diagnostic reasoning involves several cognitive tasks that result in the establishment of a diagnostic hypothesis. Usually, a single clinical datum is not sufficient to establish a diagnosis with certainty (Lopes, Silva, \& Araujo, 2012). Thus, the knowledge about the accuracy of 
Table 1

Operational definitions for the defining characteristics of ineffective breathing pattern.

\begin{tabular}{|c|c|}
\hline Defining characteristics & Operational definitions \\
\hline Alterations in depth of breathing & $\begin{array}{l}\text { Increased or decreased thoracic expansion or abnormal retraction of the rib cage during breathing cycles. } \\
\text { Alterations in depth of breathing can be evaluated by inspection of the thoracic expansibility and by } \\
\text { diaphragmatic expansibility measurements. }\end{array}$ \\
\hline Altered chest excursion & $\begin{array}{l}\text { Asymmetry of the movements of the thoracic cage. Altered chest excursion can be evaluated by inspecting the } \\
\text { chest movements with breathing for symmetry. }\end{array}$ \\
\hline Bradypnea & $\begin{array}{l}\text { Number of breathes (inhales and exhales) per unit of time that is lower than } 12 \text { breaths per minute. } \\
\text { Bradypnea can be evaluated by inspection. }\end{array}$ \\
\hline Dyspnea & $\begin{array}{l}\text { Labored or difficult breathing. } \\
\text { Dyspnea can be evaluated by patients' report of "shortness of breath" or that they "can't get enough air". }\end{array}$ \\
\hline Increased anterior-posterior diameter & $\begin{array}{l}\text { Anteroposterior diameter that is greater than the latero-lateral diameter. } \\
\text { Increased anterior-posterior diameter can be evaluated by measuring the chest diameters and by verifying a } \\
\text { relationship between anteroposterior and transverse diameter greater than } 1: 2 \text {. }\end{array}$ \\
\hline Orthopnea & $\begin{array}{l}\text { Appearance of worsening of dyspnea while in horizontal position. } \\
\text { Orthopnea can be evaluated by inspection or asking about the position adopted by the patient. }\end{array}$ \\
\hline $\begin{array}{l}\text { Prolonged expiration phase } \\
\text { Pursed-lip breathing }\end{array}$ & $\begin{array}{l}\text { A ratio between the inspiratory and expiratory time that is greater than } 1: 2 \text {. Prolonged expiration phase can be evaluated by inspection. } \\
\text { A respiratory pattern characterized by breathing in through the nose and out by means of pursed lips. } \\
\text { Pursed-lip breathing can be evaluated by inspection and require the examiner to ask if the patient was taught to } \\
\text { breathe using pursed-lips breathing. }\end{array}$ \\
\hline Tachypnea & $\begin{array}{l}\text { Number of breathes (inhales and exhales) per unit of time that exceeds } 20 \text { breaths per minute. } \\
\text { Tachypnea can be evaluated by inspection. }\end{array}$ \\
\hline Use of accessory muscles to breathe & $\begin{array}{l}\text { Contraction of the trapezius, sternocleidomastoid, internal intercostal, scalene, pectoralis major, } \\
\text { or abdominal muscles during with breathing. Use of accessory muscles to breathe can be evaluated by inspection. }\end{array}$ \\
\hline
\end{tabular}

defining characteristics is important, as it increases the nurses' ability to discriminate between patients with and without a specific nursing diagnosis. This study aimed to analyze the accuracy of the defining characteristics of IBP in cardiac surgery adult patients.

\section{Materials and methods}

\subsection{Design and setting}

An accuracy study was carried out in the heart surgery ICU of a 349bed referral hospital in a large city located in north-eastern Brazil. This unit is exclusive for adult patients in the post-operative period and most patients remain in the unit for 48 hours or more after surgery. At this hospital, the documentation of nursing diagnoses is paper-based and consists in a checklist of potential nursing diagnoses.

To ensure a more precise identification of IBP, the list of nursing diagnoses inferred by the nurses in this ICU was not used. The method used to identify IBP in this study was based in conceptual and operational definitions, as described further in the Data collection section.

\subsection{Sample}

Consecutive sampling was adopted in this study. Sample size was calculated using the formula for single test accuracy studies (Zhou, Obuchowski, \& McClish, 2002) with a confidence level of 95\% desired width of one half of $95 \%$, confidence interval of $10 \%$, and a conjectured sensitivity of $85 \%$, leading to a total of 98 patients. Patients aged 18 years and older, who were in the period between 24 and 48 hours following cardiac surgery, and who had a level of consciousness that would enable data collection were included.

For safety reasons, exclusion criteria for this study included mechanical ventilation, heart transplantation, and end-stage comorbidities. Ethical approval for the study was granted by the appropriate local research ethics committee and all participants signed an informed consent form.

\subsection{Data collection}

Data collection was carried out by two nurse researchers who individually assessed the patients and reviewed their medical records for complementary information, when necessary. A third researcher was responsible for observing and supervising the data collection, and for making the diagnostic inferences. This third researcher was chosen as an expert for having a high level experience with respiratory diagnoses from the NANDA-I taxonomy gained during 10 years participation in a research project on nursing diagnoses, interventions and outcomes, and for authoring several publications focusing on respiratory nursing diagnoses.

A data collection instrument was created for use in this study and comprised three sections: respiratory symptoms and measures of pulmonary function, a guide for the respiratory assessment of the patients, and a list of operational definitions for each defining characteristic of IBP, as listed in the NANDA-I taxonomy 2012-2014 (the current version at the time data collection was carried out). Presently, the NANDA-I taxonomy 2015-2017 is the current version. However, there are no differences regarding the 2012-2014 and 2015-2017 versions of the NANDA-I taxonomy in regard to the defining characteristics of IBP. Operational definitions were extracted from the literature (Seidel et al., 2011; Swartz, 2010) and can been seen in Table 1.

The respiratory assessment did not include a spirometry test, because the clinical condition of the patients was not compatible with it. Thus, the following defining characteristics that are suggested by NANDA-I for the assessment of IBP were not assessed in this study: decreased expiratory pressure, decreased inspiratory pressure, decreased minute ventilation, and decreased vital capacity. The defining characteristic "nasal flaring" that is also present in the NANDA-I taxonomy was not assessed for being seen mostly in infants and younger children (Seidel et al., 2011). The defining characteristic "use of three-point position" was not assessed because, at this hospital unit, the patients are recommended to be laid down on bed during the entire postoperative period, except during procedures and physical therapy.

\subsection{Data analysis}

All analyses were performed using the R software version 3.0.2 ( $R$ Core Team, 2014). After the inferential process, measures of statistical accuracy were calculated for each defining characteristic. In this study, sensitivity (Se) can be understood as the probability of correctly identifying the presence of a defining characteristic in patients with IBP. Specificity (Sp) represents the opposite, i.e. the probability of correctly identifying the absence of a defining characteristic in patients without IBP. The positive predictive value $(\mathrm{PV}+)$ represents the probability of having IBP in patients with a defining characteristic, while the negative predictive value ( $\mathrm{PV}-$ ) represents the probability of the 
Table 2

Prevalence of Ineffective breathing pattern and its defining characteristics in the sample.

\begin{tabular}{lllll}
\hline Variables & Presence & $\%$ & Absence & $\%$ \\
\hline Ineffective breathing pattern & 23 & 23.5 & 75 & 76.5 \\
Defining characteristics & & & & \\
$\quad$ Alterations in depth of breathing & 68 & 69.4 & 30 & 30.6 \\
Tachypnea & 30 & 30.6 & 68 & 69.4 \\
Dyspnea & 27 & 27.6 & 71 & 72.4 \\
Orthopnea & 25 & 25.5 & 73 & 74.5 \\
Prolonged expiration phase & 14 & 14.3 & 84 & 85.7 \\
Altered chest excursion & 9 & 9.2 & 89 & 90.8 \\
Pursed-lip breathing & 4 & 4.1 & 94 & 95.9 \\
Bradypnea & 7 & 7.1 & 91 & 92.9 \\
Increased anterior-posterior diameter & 1 & 1.0 & 97 & 99.0 \\
Use of accessory muscles to breathe & 1 & 1.0 & 97 & 99.0 \\
\hline
\end{tabular}

absence of IBP in patients without a defining characteristic (Lopes et al., 2012).

The likelihood ratio (LR) is the probability of the presence/absence of a defining characteristic in patients with IBP divided by the same probability in those without IBP. Likelihood ratios can be calculated for the presence of a defining characteristic (LR+) and for the absence of a defining characteristic (LR-). Under most circumstances, likelihood ratios greater than 10 and less than 0.1 hold strong evidence to confirm or deny diagnoses, respectively (Deeks \& Altman, 2004).

The diagnostic odds ratio (DOR) measures the chance of a patient being diagnosed with IBP when a defining characteristic is present. Statistical significance is established for both the LR and the DOR at a $95 \%$ confidence interval that does not include the numeral 1. Finally, the area under the receiver operating characteristic (ROC) curve is used to summarize the accuracy of various defining characteristics. Values for the area under the ROC curve that is close to 1 indicate high accuracy (Zhou et al., 2002).

\section{Results}

The patients were predominantly male (55.1\%) and either married or cohabitating (70.4\%), and $76.5 \%$ were low-educated (i.e. elementary education). The patients' mean age was 55.9 years (SD 13.4). The most prevalent medical diagnoses were angina/coronary artery disease (37.8\%), and the most frequent types of surgery were coronary artery bypass grafting (59.1\%) and valve replacement (37.8\%). With regard to personal habits, $54.1 \%$ of participants were currently or had been smokers at some point in their lives. No changes were found in the assessment of vital signs and oxygen saturation.

In accord with the specialist's inferences, the nursing diagnosis of IBP was present in $23.5 \%$ of the sample. The most frequent defining characteristics can be seen in Table 2 .

Among the 10 defining characteristics that could be legitimately connected to IBP, only 3 had positive or negative LRs that were not significant (i.e. their 95\% confidence interval included the numeral 1): bradypnea, increased anteroposterior diameter, and use of accessory muscles to breathe. Alterations in depth of breathing and pursed-lip breathing were the most sensitive defining characteristics (high Se, PVand DOR values, LR - below 0.1, and ROC close to 1 ). On the other hand, altered chest excursion and prolonged expiration phase were the most specific (high Sp, PV + and DOR values, LR+ above 10, and ROC close to 1) (Table 3).

Analysis of the area under the ROC curve confirmed the other results and showed that alterations in depth of breathing and pursed-lip breathing are sensitive defining characteristics (high true positive and false positive rates), while the absence of altered chest excursion and prolonged expiration phase are specific (high true positive and low false positive rates) (Fig. 1).

\section{Discussion}

The most important finding from this study is that some defining characteristics were more closely related with IBP than others, hence the importance of diagnostic accuracy studies for facilitating the identification of nursing diagnosis. Alterations in depth of breathing and pursed-lip breathing behaved as sensitive defining characteristics of IBP, while altered chest excursion and prolonged expiration phase behaved as specific.

Assessment of respiratory depth stands out among the main activities performed by nurses for patients with respiratory problems (Sousa et al., 2013). Depth of breathing is related to the tidal volume, which is the amount of air inspired during normal, relaxed breathing. Conditions that affect the mechanics of lung and chest wall (like heart surgery), have a direct impact on the tidal volume and hence in the depth of breathing (Ali, Weisel, Layug, Kripke, \& Hechtman, 1974).

Pursed-lip breathing was one of the highly sensitive defining characteristics of IBP. No studies were found on adult cardiac patients that addressed this defining characteristic. However, in a study performed on children with congenital heart diseases, pursed-lip breathing was one of the seven defining characteristics that presented statistically significant differences between patients with and without IBP (Beltrao et al., 2011).

Assessment of pursed-lip breathing was caution-oriented in this study, since this is also a nursing intervention to promote respiratory comfort. When performing the patients' assessment, the expert nurse ensured that the patients who were breathing with pursed lips were acting spontaneously, and not using a breathing teaching that was taught to them.

Altered chest excursion is usually associated with unilateral ventilation problems (Sole, Klein, \& Moseley, 2013) which are common even following minimally invasive cardiac surgical procedures (Tutschka, Bainbridge, Chu, Kiaii, \& Jones, 2015). In spite of being frequent, this type of adverse event carries significant morbidity and requires early detection and intervention. Although altered chest excursion was closely related to IBP in the study, the same may not be true in patients that are still under mechanical ventilation, as reported elsewhere (Zeitoun et al., 2007).

Table 3

Accuracy measures of the defining characteristics of ineffective breathing pattern ${ }^{\mathrm{a}}$.

\begin{tabular}{|c|c|c|c|c|c|c|c|c|}
\hline Defining characteristics & Se & Sp & $\mathrm{PV}+$ & PV- & $\mathrm{LR}+$ & LR- & DOR & ROC \\
\hline Alterations in depth of breathing & 95.65 & 38.67 & 32.35 & 96.67 & $1.56[1.24-1.95]$ & $0.11[0.02-0.78]$ & $12.07[2.32-298.45]$ & 0.671 \\
\hline Altered chest excursion & 30.43 & 97.33 & 77.78 & 82.02 & $11.41[2.79-46.76]$ & $0.71[0.54-0.94]$ & $14.64[3.10-116.58]$ & 0.638 \\
\hline Bradypnea & 17.39 & 96.00 & 57.14 & 79.12 & $4.35[1.35-14.03]$ & $0.86[0.71-1.04]$ & $4.89[0.95-28.52]$ & 0.567 \\
\hline Dyspnea & 56.52 & 81.33 & 48.15 & 85.92 & $3.03[1.73-5.30]$ & $0.53[0.33-0.86]$ & $5.51[2.02-15.74]$ & 0.689 \\
\hline Increased anterior-posterior diameter & 98.68 & 8.00 & 76.53 & 66.67 & $1.07[0.93-1.24]$ & $0.16[0.02-1.74]$ & $6.01[0.47-194.41]$ & 0.533 \\
\hline Orthopnea & 52.17 & 82.67 & 48.00 & 84.93 & $3.01[1.68-5.40]$ & $0.58[0.37-0.90]$ & $5.07[1.84-14.49]$ & 0.674 \\
\hline Prolonged expiration phase & 56.52 & 98.67 & 92.86 & 88.10 & $42.39[5.94-302.66]$ & $0.44[0.28-0.70]$ & $79.41[13.57-2074.52]$ & 0.775 \\
\hline Pursed-lip breathing & 98.68 & 20.00 & 78.95 & 83.33 & $1.23[1.01-1.51]$ & $0.07[0.01-0.54]$ & $16.37[2.35-450.61]$ & 0.593 \\
\hline Tachypnea & 56.52 & 77.33 & 43.33 & 85.29 & $2.49[1.49-4.19]$ & $0.56[0.35-0.91]$ & $4.34[1.62-12.07]$ & 0.669 \\
\hline Use of accessory muscles to breathe & 98.68 & 8.00 & 76.53 & 66.67 & $1.07[0.93-1.24]$ & $0.16[0.02-1.74]$ & $6.01[0.47-194.41]$ & 0.533 \\
\hline
\end{tabular}

a Se: Sensitivity; Sp: Specificity; PV: predictive value; LR: likelihood ratio; DOR: diagnostic odds ratio; ROC: area under ROC curve. 


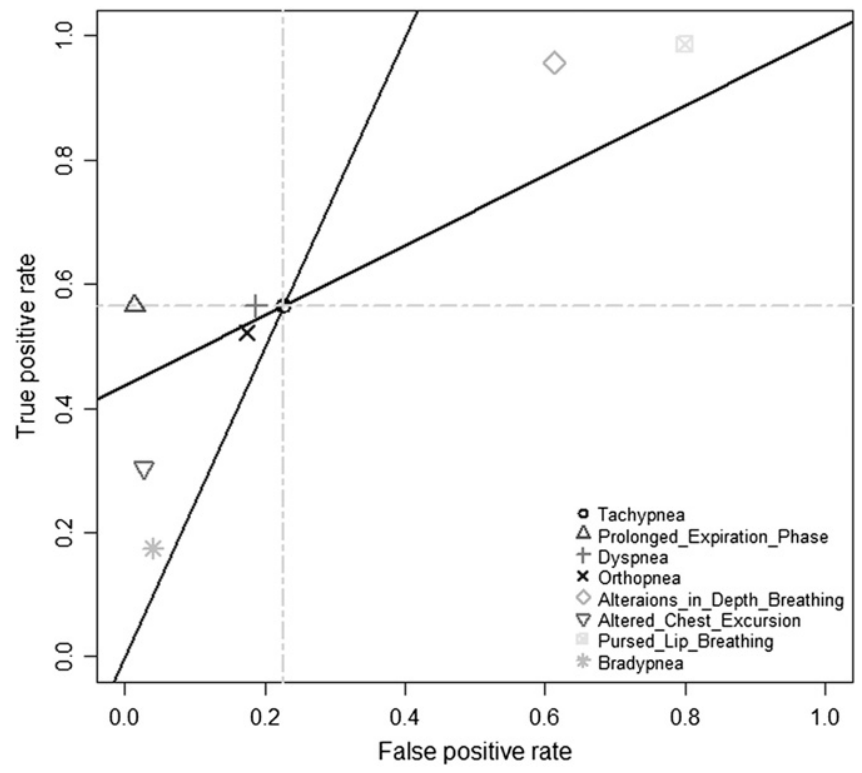

Fig. 1. Performance comparison of defining characteristics with the largest area under the ROC curve.

Prolonged expiration phase is defined as an increase in the time taken to exhale air (Beltrao et al., 2011). This sign manifests itself in patients having difficulty breathing in order to maintain a high airway pressure (Singer, 2009). No studies were found concerning this defining characteristic, which may reflect a literature gap.

The high percentage of smokers (corresponding to $54.1 \%$ ) was of particular interest. Although other investigations would be necessary to establish relationships between this and other findings, it is known that smoking increases the risk of developing respiratory complications in the postoperative period (Lee et al., 2015).

The findings indicate the importance for nurses to maintain skills in physical examination, especially in postoperative units. The availability of sophisticated technology can lead nurses to underuse clinical examination data, which are essential for the correct identification of nursing diagnoses. In addition, a revision of the defining characteristics of IBP that are listed in the NANDA-I taxonomy would be beneficial to facilitate the assessment of this nursing diagnosis by nurses. For example, NANDA-I recommends the use of measures such as expiratory and inspiratory pressures, minute ventilation, and vital capacity that are helpful to the assessment of IBP, but require a physician's order or prescription. We believe that defining characteristics that can be assessed by nurses, in an independent manner, should receive more emphasis.

It is important for nurses to understand and exercise clinical skills within the nursing domain when evaluating the patients' responses instead of basing their clinical assessment on results from tests that require medical technology. The improvement of clinical nursing skills is crucial for autonomous nursing care and for the effective assessment of postoperative patients, leading to early detection of complications and effective care management (Brier et al., 2015).

\subsection{Limitations}

This study has two main limitations. First, only one expert nurse was responsible for making the diagnostic inferences, which is recognized to be an imperfect gold standard. At the time the study was developed, theories and most rigorous methods for establishing the accuracy of defining characteristics were still under development. These new methodologies were recently published and represent a new trend in research on nursing diagnoses (Lopes, Silva, Araujo, \& Silva Filho, 2015; Lopes et al., 2012).
Second, while associations between some defining characteristics and IBP have been demonstrated for the sample of cardiac surgical patients, the ability of the physical assessment to identify respiratory compromise in more critically ill patients remains to be determined. As stated before, safety issues were an obstacle for the inclusion of patients with a wider range of physical responses in the sample. There would be benefit in conducting additional research involving patients with different clinical profiles.

\section{Conclusions}

This study showed that alterations in depth of breathing, altered chest excursion, prolonged expiration phase, and pursed-lip breathing are accurate defining characteristics of IBP in cardiac surgery adult patients. Knowledge of the accuracy of the defining characteristics of respiratory nursing diagnoses can guide nurses to a more appropriate diagnostic inference, which directly impacts the patient safety and the quality of the nursing care.

\section{Implications for research, practice and policy}

The results of this study have implications for research, clinical practice, and policy. The methods that were used to estimate the accuracy of the defining characteristics of IBP can be replicated by researchers interested in accuracy assessments of other defining characteristics or even other nursing diagnoses.

The accuracy values that are documented here may be useful for nurses working in the cardiac postoperative setting, since they reduce the subjectivity that is common in the clinical assessment of patients.

With regard to policy, the accurate assessment of postoperative events like ineffective breathing pattern can impact the detection of respiratory complications and increase the scope of decision-making by policy-makers.

\section{References}

Ali, J, Weisel, RD, Layug, AB, Kripke, BJ, \& Hechtman, HB (1974). Consequences of postoperative alterations in respiratory mechanics. American Journal of Surgery, 128(3), 376-382. http://dx.doi.org/10.1016/0002-9610(74)90176-7.

Beltrao, BA, Silva, VM, Araujo, TL, \& Oliveira Lopes, MV (2011). Clinical indicators of ineffective breathing pattern in children with congenital heart diseases. International Journal of Nursing Terminologies and Classifications, 22(1), 4-12. http://dx.doi.org/10. 1111/j.1744-618X.2010.01169.X.

Brier, J, Carolyn, M, Haverly, M, Januario, ME, Padula, C, Tal, A, \& Triosh, H (2015). Knowing 'something is not right' is beyond intuition: Development of a clinical algorithm to enhance surveillance and assist nurses to organise and communicate clinical findings. Journal of Clinical Nursing, 24(5-6), 832-843. http://dx.doi.org/10.1111/jocn. 12670 .

Deeks, JJ, \& Altman, DG (2004). Diagnostic tests 4: Likelihood ratios. BMJ, 329(7458), 168-169. http://dx.doi.org/10.1136/bmj.329.7458.168.

Herdman, TH, \& Kamitsuru, S (2014). NANDA international nursing diagnoses: Definitions $\mathcal{E}$ classification, 2015-2017. Oxford: Wiley-Blackwell.

Lee, A, Chui, PT, Chiu, CH, Tan, PE, Tam, TP, Samy, W, ... Gin, T (2015). Risk of perioperative respiratory complications and postoperative morbidity in a cohort of adults exposed to passive smoking. Annals of Surgery, 261(2), 297-303. http://dx.doi.org/10.1097/ SLA.0000000000000544.

Lopes, MV, Silva, VM, \& Araujo, TL (2012). Methods for establishing the accuracy of clinical indicators in predicting nursing diagnoses. International Journal of Nursing Knowledge, 23(3), 134-139. http://dx.doi.org/10.1111/j.2047-3095.2012.01213.x.

Lopes, MVO, Silva, VM, Araujo, TL, \& Silva Filho, JV (2015). Statistical characteristics of the weighted inter-rater reliability index for clinically validating nursing diagnoses. International Journal of Nursing Knowledge, 26(4), 150-155. http://dx.doi.org/10. 1111/2047-3095.12047.

Pascoal, LM, Lopes, MV, Silva, VM, Beltrao, BA, Chaves, DB, Santiago, JM, \& Herdman, TH (2014). Ineffective breathing pattern: Defining characteristics in children with acute respiratory infection. International Journal of Nursing Knowledge, 25(1), 54-61. http://dx.doi.org/10.1111/j.2047-3095.2013.01249.x.

R Core Team (2014). R: A language and environment for statistical computing. from http://www.r-project.org/

Seidel, HM, Ball, JW, Dains, JE, Flynn, JA, Solomon, BS, \& Stewart, RW (2011). Mosby's physical examination handbook. St Louis: Elsevier.

Singer, MWA (2009). Oxford handbook of critical care. Oxford: Oxford University Press.

Sole, ML, Klein, DG, \& Moseley, MJ (2013). Introduction to critical care nursing. Missouri: Elsevier Saunders. 
Sousa, VE, Lopes, MVO, Araujo, TL, Rolim, IL, Nascimento, RV, \& Oliveira, TF (2013). Clinical indicators of ineffective airway clearance for patients in the cardiac postoperative period. European Journal of Cardiovascular Nursing, 12(2), 193-200. http://dx.doi.org/ 10.1177/1474515112443931.

Stephens, RS, Shah, AS, \& Whitman, GJ (2013). Lung injury and acute respiratory distress syndrome after cardiac surgery. The Annals of Thoracic Surgery, 95(3), 1122-1129. http://dx.doi.org/10.1016/j.athoracsur.2012.10.024.

Swartz, MH (2010). Textbook of physical diagnosis: History and examination. Philadelphia: Elsevier.
Tutschka, MP, Bainbridge, D, Chu, MW, Kiaii, B, \& Jones, PM (2015). Unilateral postoperative pulmonary edema after minimally invasive cardiac surgical procedures: A case-control study. The Annals of Thoracic Surgery, 99(1), 115-122. http://dx.doi.org/10.1016/j.athoracsur:2014.07.067.

Zeitoun, SS, Barros, AL, Michel, JL, \& Bettencourt, AR (2007). Clinical validation of the signs and symptoms and the nature of the respiratory nursing diagnoses in patients under invasive mechanical ventilation. Journal of Clinical Nursing, 16(8), 1417-1426. http:// dx.doi.org/10.1111/j.1365-2702.2006.01632.x.

Zhou, XH, Obuchowski, NA, \& McClish, DK (2002). Statistical methods in diagnostic medicine. New York: Wiley-Interscience. 